\title{
PROBLEMS OF WOMEN WITH HIGH RISK OF ABANDONMENT OF A NEWBORN
}

\author{
Tetiana Liakh \\ Borys Grinchenko Kyiv University, Ukraine \\ Nataliia Hevchuk \\ Kamianets-Podilskyi Ivan Ohienko National University, Ukraine
}

\begin{abstract}
The research focuses on the identification of types of social and preventive work with women in women's consultations and maternity clinics to prevent abandonment of a newborn. The purpose of the research is to identify typical problems and needs of mothers in risk of abandoning a newborn. In the article, authors describe results of in-depth interviews of mothers who have been, or are at high risk of abandoning a newborn. Identified problems authors grouped into two main groups: psychological and social problems. In addition, the authors conducted a series of focus groups with health workers in delivery departments and women's consultations, and as a result - suggested a categorization of factors influencing on abandoning a child in the first two years. These factors were grouped by the authors into two main categories: "personal" and "reference" factors. Further, based on expert survey of social workers, the authors developed recommendations for providing various social and preventive services to mothers who are willing to abandon a child. Developed recommendations reflect the following types of support: psychological support, social-pedagogical support, medical support and rehabilitation.
\end{abstract}

Keywords: abandonment of a newborn; early motherhood; infancy; motherhood; prevention of child abandonment; social prevention; young child.

\section{Introduction}

A woman's abandoning from her newborn is one of the form of deviant behavior. Although this phenomenon is a widespread, but so far, it is poorly studied socio-psychological one, which became extremely relevant in Ukraine due to the deterioration of the socio-economic situation, complicated by military actions in the East.

The need to research the causes of such abandoning, and further development and implementation of measures for social prevention of this phenomenon, dictated by the concern of children's doctors, an increase in the number of children abandoned by mothers at an early age. As well as social workers due to the negative consequences for health and the fate of the early separation for the child from the biological mother, the growth of orphanhood. 
Social prevention of abandonment among female infants with such a risk is relevant area of social work in Ukraine. In order to implement qualified and effective social prevention of this phenomenon, it is necessary to identify the problems and needs of women who are at risk of abandonment of a newborn.

\section{Literature review}

A study of the problems of mothers who are at risk of abandonment a child in early stages is a concern for many scholars.

David L. Ransel (2014) made a historical analysis of socio-economic causes of mother's failure from children in Russia.

Research team (Miller, Miceli, Whitman, \& Borkowski, 1996) noting that the woman's willingness to become a mother effects on development of a child after birth. In addition, researchers emphasize the importance of women's awareness and willingness to fulfill the role of mother, the influence of conscious parenting on the emotional and intellectual development of the child.

The authors of the study «Cognitive readiness to parent and intellectualemotional development in children of adolescent mothers» (Mangeli, Rayyani, Cheraghi, \& Tirgari, 2018) determine relationships among prenatal maternal knowledge and attitudes about parenting.

Margaret M. Coady in research «Feminism and the Development of Early Childhood Education in Australia. Feminism(s) in Early Childhood» (2017) considered the impact of the emergence of childcare services on early childhood on feminist views and maternity.

In the study Yookyong Lee «Early motherhood and harsh parenting: The role of human, social, and cultural capital» (2009) emphasizes the relationship of early motherhood with rigid parenting behavior. The scientist draws attention to the importance of implementing preventive programs in schools.

I. Sjöstrand (2018) in article «The "Baby box", an issue or solution to child abandonment in South Korea» presents the results of a dissertation study that examines the impact of the "Baby box" in Korea on the abandonment of unmarried mothers from young children.

Most foreign researchers point out that women with a risk of abandonment of young children have problems with psychological health, social problems (low material income of the family, lack of relatives or their support, lack of own housing or proper living conditions in an existing home).

\section{Methodology}

The study is conducted in the Kyiv and Khmelnitsky region of Ukraine, and is aimed to identify the following: 
1. Needs and problems of women who have been, or are at risk of abandoning a new born (through in-depth interviews with women who had, or are at risk of abandoning a child after birth);

2. Key factors influencing women to abandon a newborn (through focus group with 20 health professionals of delivery departments and women's consultations);

3. Types of social support to be provided for women who intend to abandon a child at early stages (through expert interviews with social work professionals).

At the first stage of the study, we conducted in-depth interviews in Kyiv and Khmelnitsky region of Ukraine with 60 women who have been, or are at risk of abandoning a newborn. This made possible to identify their needs and problems that lead to the abandonment of a child. Respondents participated in depth interviews through telephone and oral invitations from social workers at the Centers for Social Services for Family, Children and Youth and personal letters to women who intend to abandon the child. The interview was based on open questions, the topics of which concerned the establishment of causal relationships between the needs and problems of respondents and their decision to abandon an early childhood.

All questions were united into two parts: psychological and social.

The psychological part included questions about the definition of: psychological infantilism and social maturity (expressed in the delay in the formation of personality, when human behavior does not meet age requirements; difficulties arise mainly in the emotional-volitional sphere: the inability to adequately manage their own emotions, behavior, identify and express feelings, make independent decisions, in general - the preservation of children's qualities of the individual); the locus of control (the tendency to shift responsibility for the situation to others, to avoid solving problems); level of psychological traumatism; level of self-esteem; level of stress resistance; predisposition to alcohol and / or narcotic substances.

The social part of questions was determined by: the financial situation of the family; availability of permanent work; support for relatives; availability of own accommodation, or proper living conditions; level of educational potential of a woman (experience of taking older children from the family due to improper performance of duties of child retention and upbringing); registration, presence of documents certifying the identity of a woman, in particular passport, birth certificate, etc.).

Encoding occurred at the same time as the data was collected. The initial encoding was open and close to the text, which means that the codes are designed in such a way as to accurately reflect respondents' actions and thoughts using their 
own words. The subsequent coding of the interview was the current use of benchmarking, which made it possible to identify such codes in categories.

Table 1 Information about respondents: women

\begin{tabular}{|c|c|}
\hline \multicolumn{2}{|r|}{$\mathrm{n}=60$} \\
\hline \multirow[t]{4}{*}{ Age range $(\%)$} & From 16 to $17-12(20 \%)$ \\
\hline & From 18 to $19-18(30 \%)$ \\
\hline & From 20 to $22-16(26,67 \%)$ \\
\hline & From 23 to $25-14(23,33 \%)$ \\
\hline \multirow[t]{3}{*}{ Education (\%) } & Secondary education - $25(41,67 \%)$ \\
\hline & Vocational and technical education - 29 (48,33\%) \\
\hline & High education - $6(10 \%)$ \\
\hline \multirow{2}{*}{$\begin{array}{l}\text { Risk of abandonment of } \\
\text { a newborn (\%) }\end{array}$} & Women who risk the abandonment of a newborn $-47(78,33 \%)$ \\
\hline & $\begin{array}{l}\text { Women who are at risk of abandonment of a newborn }-13 \\
(21,67 \%)\end{array}$ \\
\hline \multirow[t]{2}{*}{ Marital status (\%) } & Married - $6(10 \%)$ \\
\hline & Single - $54(90 \%)$ \\
\hline
\end{tabular}

At the second stage of the study, we conducted a focus group of 20 maternity health care workers and women's counseling to determine the factors of abandonment of a child at the early stages. Respondents were attracted to the focus groups through official letters addressed to the directors of medical institutions. Respondents were offered a series of open questions that prompted an exchange of views on the reasons for the abandoning of women from young children established by healthcare professionals when counseling such women or their care. The responses were thoroughly analyzed and some minor changes made.

Table 2 Information about respondents: health care workers

\begin{tabular}{|l|l|}
\hline \multicolumn{2}{|c|}{$\mathrm{n}=20$} \\
\hline Age range & $23-55$ \\
\hline \multirow{2}{*}{ Gender (\%) } & Male $-4(20 \%)$ \\
\cline { 2 - 2 } & Female $-16(80 \%)$ \\
\hline \multirow{2}{*}{$\begin{array}{l}\text { Represented institution } \\
(\%)\end{array}$} & Maternity hospital - 7 (35\%) \\
\cline { 2 - 2 } Education (\%) & Women's consultation - 13 $(65 \%)$ \\
\hline \multirow{2}{*}{$\begin{array}{l}\text { Professional Experience, } \\
\text { years (\%) }\end{array}$} & High education $-20(100 \%)$ \\
\cline { 2 - 2 } & From 1 to 5 years - 2 (10\%) \\
\cline { 2 - 2 } & From 6 to 10 years $-4(20 \%)$ \\
\cline { 2 - 2 } & From 11 to 14 years $-9(45 \%)$ \\
\hline
\end{tabular}


In the third stage, we conducted an expert interview with 72 social work professionals of Centers for Social Services for Family, Children and Youth, which specialized social services, counseling points) to identify the types of social support that women most in need of abandoning a newborn child. Respondents were interviewed through suggestions in their personal invitations to social service directors.

Table 3 Information about respondents: social workers

\begin{tabular}{|l|l|}
\hline \multicolumn{2}{|c|}{$\mathrm{n}=72$} \\
\hline Age range (\%) & From 23 to 28 years - 8 (11.11\%) \\
\cline { 2 - 2 } & From 29 to 33 years - 10 (13.9\%) \\
\cline { 2 - 2 } & From 34 to 38 years - 16 (22.22\%) \\
\cline { 2 - 2 } From 39 to 43 years - 14 (19.44\%) \\
\cline { 2 - 2 } From 44 to 48 years - 17 (23.61\%) \\
\cline { 2 - 2 } institution (\%) & From 49 to 53 years - 7 (9.72\%) \\
\hline Education (\%) & High education - 72 (100\%) \\
\hline & $\begin{array}{l}\text { Psychologists, obstetricians and gynecologists who work at } \\
\text { counseling centers in city and regional maternity hospitals - 23 } \\
\text { (31.94\%) }\end{array}$ \\
\cline { 2 - 2 } & $\begin{array}{l}\text { Leading Social Workers and Psychologists at Centers for Social } \\
\text { Services for Family, Children and Youth - 22 (30.56\%) }\end{array}$ \\
\cline { 2 - 2 } & $\begin{array}{l}\text { Social educators, psychologists, teachers-rehabilitators of } \\
\text { Centers for mother and child health - 19 (26.39\%) }\end{array}$ \\
\cline { 2 - 2 } & The specialists of institutions of social protection - 8 (11.11\%) \\
\hline
\end{tabular}

\section{Research results}

At the first stage of the study we conducted with 60 women who had or are at risk of abandoning of child in two regions of Ukraine: Kyiv and Khmelnitsky. They began with questions about personal data.

The question about official status of women staying in marriage gave us the following results: $90 \%$ (54 persons) of the respondents were officially unmarried, among them: 28 persons (51.85 \%) - were in a sexual relationship with one partner, 16 persons (29.63 \%) - lived in a civil marriage, 10 persons (18.52 \%) became pregnant from a casual partner.

By examining the personal data of respondents, we determined that $45 \%$ of women were from residential institutions; $30 \%$ - were brought up in incomplete families; $25 \%$ - of full families.

Concurrently, at the time of the decision to abandon of child, $80 \%$ of women did not have a permanent place of residence $(66.67 \%$ lived in the rented 
accommodation, $25 \%$ lived temporarily in their relatives, $8.33 \%$ did not have anywhere live); $20 \%$ of women lived with their parents.

Equally important, in our opinion, is the availability of appropriate vocational education and a permanent place of work for a woman who is preparing to become a mother. Therefore, our next question was whether women have vocational education. The answers were as follows: $41.67 \%$ have a certificate of general secondary education; $48.33 \%$ - received vocational education; and only $10 \%$ indicated that they had completed a higher education institution and received a bachelor's degree. Regarding the permanent place of work, $31.67 \%$ of people do not work at all; $35 \%$ of people - change jobs almost monthly; $11.67 \%$ - work on seasonal work; $13.33 \%$ - are in search of work; 8,33 \% - are officially employed and have permanent material income.

An analysis of the children's memories of mothers who expressed their desire to abandon the child, suggests that $70 \%$ of them had an unlucky childhood, were constantly subjected to emotional and physical violence by relatives. Such assertions show that from childhood these women form a kind of behavioral matrix of low tolerance to open forms of aggression, and they usually solve their own life conflicts, usually with aggressive actions, including those concerning their children.

As a result of in-depth interviews, we determined that $75 \%$ of women have harmful habits: $83.33 \%$ of them smoke cigarettes, $64.29 \%$ - often use alcohol, $19.05 \%$ - sometimes use drugs, $48.34 \%$ - often change sexual partners. As a result of such a way of life in women there is a physiological unwillingness to carry the baby, which is accompanied by a large number of complications during pregnancy, the birth of premature, sick or injured babies.

By examining the social maturity of women in relation to the birth of a child, we can assert that this category of respondents has a fairly low responsibility for their own actions, since $11.67 \%$ of respondents can decide on their own, and $40 \%$ translate all responsibility into the social environment.

As a result, women who have or who are at risk of abandoning a child after birth often come from unstable families (80 \%) who report violations of childparenting relationships and intra-family relationships. They stressed that they had a high level of anxiety (90\%), lack of attention (63.33\%), anger and insult to the father of a child (95\%), fear and anxiety about their own future (85 \%).

Interesting, in our opinion, were women's responses to those who might influence their decision not to abandon their child. As the results of in-depth interviews show, for the woman the most important is support for the father of the child (95\%) and her own parents (11.67\%), the influence of friends is important for $13.33 \%$ of respondents.

An important aspect was to determine who the respondents could contact in the event of a problem of abandoning their own children. Answers were as 
follows: $1.67 \%$ - would apply to the priest; $13.33 \%$ - to friends; $31.67 \%$ - to a gynecologist; $11.67 \%$ - to parents; $80 \%$ - to the father of the child; $25 \%$ - before the psychologist; $20 \%$ - to a social worker.

The study has given us the opportunity to identify the actual problems of women who have or are at risk of abandoning a child after her birth. We united the identified problems of women into two groups: "psychological problems" and "social problems" (Figure 1).

\begin{tabular}{|l|}
\hline \multicolumn{3}{|c|}{ PSYCHOLOGICAL PROBLEMS } \\
\hline - anxiety \\
- lack of attention \\
- anger and insult to the child's father \\
- fear and anxiety about their own \\
future \\
- low responsibility for their own \\
actions \\
- unhealthy lifestyle \\
- emotional and physical abuse by \\
relatives \\
\hline
\end{tabular}

\begin{tabular}{|l|}
\hline \multicolumn{2}{|c|}{ SOCIAL PROBLEMS } \\
\hline - lack of permanent work \\
- unemployment \\
- low level of general and vocational \\
education \\
- instability of family relationships \\
- lack of support for a child's father \\
- absence of permanent place of \\
residence of official registration of \\
- absence of \\
marriage with the child's father \\
\hline
\end{tabular}

Figure 1 Problems of women who have or have a risk of abandonment of a newborn

Thus, psychological problems are dominated by: anxiety (90\%), lack of attention (63.33\%), anger and insult to the child's father (95\%), fear and anxiety about their own future (85\%), unhealthy lifestyle (75\%), low responsibility for their own actions (48.33\%), emotional and physical abuse by relatives (70 \%).

Among the social problems, such as: lack of permanent work (35\%) or unemployment (31.67\%), low level of general and vocational education (41.67\%), instability of family relationships (80 \%), lack of support for a child's father (95\%), absence of permanent place of residence (80\%), absence of official registration of marriage with the child's father (90\%).

At the next stage, we conducted a series of focus groups of 20 maternity health care workers and women's counseling to determine the factors of women who had or are at risk of abandoning of a newborn. As a result, the generalized answers of the respondents allowed certain groups to group the factors of abandonment of an newborn child into groups 2: personal and reference.

For personal factors, health workers included such as: extra-marital pregnancy (90\%); perception of pregnancy as an obstacle to self-actualization (65\%); Pregnant very young and personally immature (20\%); the expectant mother is constantly hesitant, whether to leave her pregnant or not (45\%); mother 
has passed in the past or is currently undergoing psychiatric treatment (15\%); anxiety about its future incompetence in the role of mother, not the formation of the image of a real home situation after childbirth, and the associated lack of support for the immediate social environment enhances anxiety (80 \%); pregnant woman has a high risk of having a child with a disability (15\%); a woman is incompetent in the role of mother through obvious emotional problems (70 \%); a woman is incompetent in the role of mother through reduced intellectual capacity (5\%); unrealistic expectations from the child (25\%).

The reference factors included health care workers as: lack of support from the parent of the child ( $95 \%)$; mother in childhood suffered from ill-treatment by parents or neglect (70 \%); mother has frequent changes of place of residence a year before delivery (more than two for 12 months) (65 \%); unwanted pregnancy, unstable marriage (10\%); the expectant mother did not visit doctors during pregnancy (75 \%); the pregnant woman had already given up her children or they were educated in boarding schools (30 \%); A woman during her pregnancy is as if ignoring her condition (she is very active, changes sexual partners, is observed regularly at a doctor, uses alcohol) (75\%).

Medical professionals have suggested that at least $70 \%$ of women do not know who to seek for qualified help and social support at all. The obtained results give us reason to assert that at the level of the territorial communities still there is not enough educational work to inform women (spouses) about the types of social support and social services that women are entitled to.

At the third stage of the study, we conducted an expert interview with 72 specialists working in Social service centers for families, children and youth, advisory posts at city and regional maternity hospitals, social centers for mother and child, social welfare institutions) to define types of social support provided for women who intend to abandonment of a newborn (through expert interviews with social work professionals).

During the expert interview respondents identified the types of social support that women most in need of abandoning a newborn child are most in need of (Figure 2). 


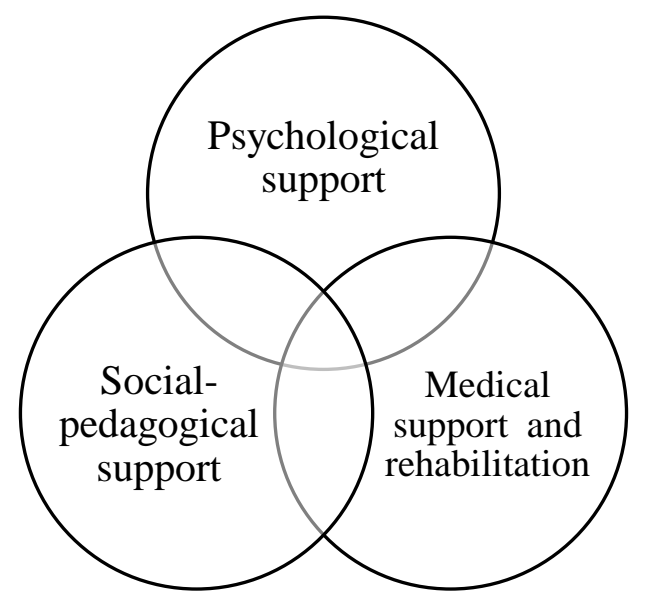

Figure 2 Types of social support for women who have or are at risk of abandonment of a newborn

First of all, it is psychological support (94.44\%), which is provided for the purpose of diagnosing the woman's psycho-emotional state, reducing her anxiety, increasing her self-esteem and self-confidence, overcoming fear, worries about her child's life, self-help learning.

There is also important material support (79.17 \%) for housing and housing conditions, assistance in arranging benefits and child benefits, receiving targeted material assistance, and housing and utility benefits.

Necessary medical support and rehabilitation (63.89 \%) is due to medical pre-natal and post-natal patronage, newborn child care skills, unplanned pregnancy prevention, healthy lifestyle advocacy.

Very important is social-pedagogical support (83.33\%). This is conducting vocational guidance work, assistance in finding a job, getting vocational or higher education.

The obtained results of research allow us to conclude that identify women who intend to abandon a newborn child done by:

- $\quad$ informing the health services of the children's service and the center of social services and support for the family, children and youth about a child that the mother did not take from a maternity home or from another health care institution;

- a personal appeal by a woman who intends to give up the child or is in difficult life circumstances that may lead to the mother's abandoning from the child;

- notices from subjects of social work with families, children and youth, bodies of executive power, bodies of local self-government, institutions, organizations and institutions of different forms of ownership and individual citizens about families (persons) who are in difficult living conditions. 
Depending on the stage at which the woman expresses the desire to give up the child (at the stage of pregnancy or after childbirth), interdepartmental interaction is built up (Figure 3).

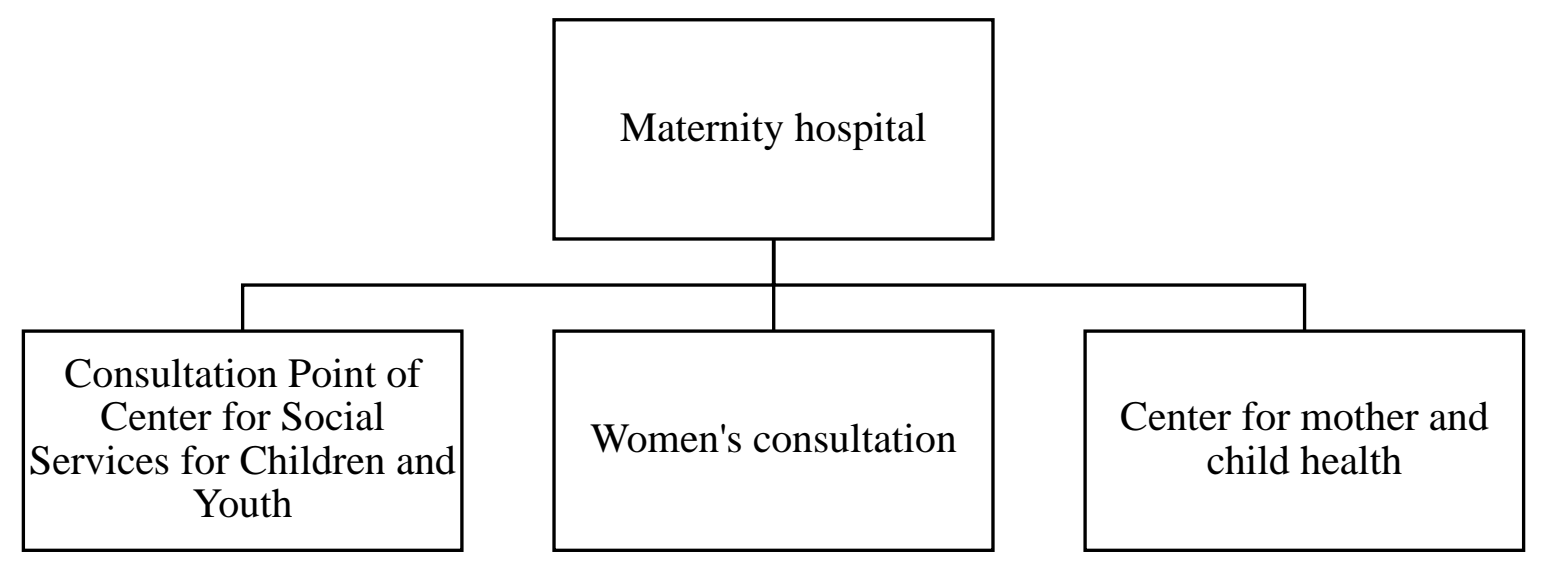

Figure 3 Scheme of interagency cooperation in case of mother's abandoning of newborn

Thus, cooperation between health care institutions, the activities of the centers for social services for the family, children and youth in maternity hospitals, and Centers for mother and child health will provide educational and preventive work among women in order to prevent early childhood abandonment.

If a woman, because of difficult living conditions (lack of income, housing, severe illness, etc.) intends to arrange a child in a residential institution, the social worker must persuade her to temporarily arrange a child in the family of a patron teacher if such an opportunity exists in the region. This will enable the child to have a family environment, keep attachment between mother and child, free women's time to overcome the difficult life circumstances in which she came through the help of specialists.

\section{Conclusions}

The study made it possible for us to identify two main groups of problems (psychological and social) of women who had or are at risk of abandoning of a newborn. In support of these problems maternity health care workers and women's counseling to determine the factors of women who had or are at risk of abandoning of a newborn. As a result, we summarized the answers of the respondents to combine the factors of women who had or are at risk of abandoning of a newborn in 2 groups: personal and reference. The received information allowed to determine the types of social support for women who had or are at risk of abandoning of a newborn: psychological, socio-pedagogical and medical support and rehabilitation. This allowed to offer the scheme of interagency cooperation in case of mother's abandoning of newborn. Therefore, established cooperation 
between health care institutions, counseling centers of the Centers for Social Services for Family, Children and Youth in Maternity Hospitals, and women's consultations with Centers for mother and child health will provide effective educational and preventive work among women in order to prevent early childhood abandonment and spreading the phenomenon of social orphanhood. The proposed social support focus on the needs and problems of such women, and also take into account the factors that lead to the abandonment of newborn.

Main findings and conclusions of the study were discussed and positively evaluated by group of experts from Department of Social Pedagogy and Social Work of Institute of Human Sciences of the Boris Grinchenko Kyiv University; Department of Social Pedagogy and Social Work of the Kamianets-Podilsky National University named after Ivan Ogienko.

\section{Acknowledgements}

The study was conducted in the framework of the scientific themes of the Institute of Human Sciences of the Boris Grinchenko Kyiv University «Personality in conditions of social transformations of modern Ukraine», registration number: 0116U002960, deadline - 5.2016-5.2021.

\section{References}

Mangeli, M., Rayyani, M., Cheraghi, M. A., \& Tirgari, B. (2018). Iranian mothers’ experiences of the outcomes of early motherhood: A qualitative study. Social work in public health, 33(3), 163-172. DOI: http//doi.org/10.1080/19371918.2018.1425648

Margaret M. Coady. (2017). Feminism and the Development of Early Childhood Education in Australia. Feminism(s) in Early Childhood, 11-24.

Miller, C. L., Miceli, P. J., Whitman, T. L., \& Borkowski, J. G. (1996). Cognitive readiness to parent and intellectual-emotional development in children of adolescent mothers. Developmental Psychology, 32(3), p. 533-541. DOI:10.1037//0012-1649.32.3.533

Ransel, D. L. (2014). Mothers of misery: Child abandonment in Russia. Princeton University Press, 329.

Sjöstrand, I. (2018). The "Baby box", an issue or solution to child abandonment in South Korea. Stockholm University, Department of Asian, Middle Eastern and Turkish Studies, 38.

Yookyong Lee (2009). Early motherhood and harsh parenting: The role of human, social, and cultural capital, Child Abuse \& Neglect, 33(9), 625-637. DOI: 10.1016/j.chiabu.2009.02.007 